\title{
Case Study of a 22-year-old student suffering from crippling migraine attacks
}

\author{
Pawandeep Singh \\ Bhagwant University, Ajmer, Rajasthan, India
}

\section{KEY WORDS}

Pain

Migraine

Ayurveda

Yoga

\section{*Corresponding Author:}

Pawandeep singh, PhD

Bhagwant University, Ajmer, Rajasthan, india

Contact no: +91-9814944500

E-mail: pdschawla@gmail.com

\begin{abstract}
A 22 year old patient with symptoms of intense migraine with history of headaches that sometimes lasted upto 2 days have made her bedridden completely. The patient ignored the mild headache which were started 4 years back. Slowly the episodes started increasing in intensity and duration ultimately culminating in a fear psychosis as the attacks did not have any fixed pattern and could strike anywhere at any time. The patient consulted many consulted several doctors for many months and had even tried acupressure but failed to find any relief from the headache. The patient approached Rudraksh Ashtang Yoga Center and enrolled herself for Yoga therapy. After 6 months of Yoga intervention the patient was back to her normal routine life.
\end{abstract}

doi: 10.38205/imcr.020258

\section{Introduction}

Migraine is a very common health condition which is not completely understood in medical practice. It is a form of severe headache which starts light but later results in a throbbing pain. It ranges from 5 to 20 minutes to less than an hour in pain. Migraine has deep effects on a patient's psychological, social, and economic status. It affects the patient's quality of life and has a great impact on their family. In this case report, the therapeutic effects of Yogic practices on a patient's migraine condition have been reported. Yoga and other alternative integrative therapies claim significant improvement among patients with severe headache and also have provided evidence for management of migraine $(7,8,9)$.

\section{Case Presentation}

The patient is a 22 year old female student, showing the classical symptoms of intense migraine attack which eventually made her completely bedridden. The headaches started two years ago. Initially, the patient suffered from mild headaches. Sometimes the headache continued for two days and the condition became worse, leaving the patient bedridden for days. The patient ignored the symptoms in the beginning after which she took help of relaxation techniques. The relaxation techniques didn't work and the duration of headache continued to increase This ultimately culminated in fear psychosis as the migraine attacks did not have any fixed pattern and could strike anywhere at any time. The patient also took allopathy medicine for a period of a year to control her symptoms but found little relief. It was noted that she had already consulted several doctors and had even tried acupressure but failed to find any relief. Then, the patient enrolled herself for
Yoga therapy at Rudraksh Ashtang Yoga Center. After observing and analyzing her daily habits for 48 hours, the following observations were made.

The patient first showed symptoms of severe headache in December 2018 followed by the episodes of migraine which continued for 2-3 days. The patient showed symptoms like heaviness of the head and lack of focus in her daily activities. The patient first developed pain in the lower portion of her neck in the back which further precipitated into migraine.

Before starting the therapy, the patient was under observation for 48-hours. The observations made for the patient revealed certain abnormalities in her sitting, standing and sleeping postures especially while studying, using laptop and mobile. The patient had developed kyphosis- a cervical pain caused due to constant forward head position. Because of the constant forward bending, she had developed compression in her vertebrae which was translating into episodes of migraine due to compression of nerves. She was continuously bending forward while studying on the bed and while sleeping. The exaggerated use of the pillow was resulting in further compression of the cervical joints. These wrong standing, sleeping and sitting posture was diagnosed as the root cause of migraine episodes that had resulted in a permanent reduction of gap between her cervical vertebrae $(2,3,4)$.

\section{Ashtanga Yoga for healthy spinal cord}

The Ashtanga Yoga scriptures prescribe that the maintenance of intervertebral discs is important for spinal health. As per prognosis, the faulty posture was resulting in overstretched muscles that could no longer keep the neck erect as they 
became weak. Gradually, the spinal vertebrae start to move from the original position which alters the space between. These intervertebral spaces eventually get reduced as one gets older. Similar results were revealed in her X-ray and CT scan. Thus, her case was clearly related to her lifestyle $(1,6)$.

\section{Intervention Protocol}

As per the Ashtanga Yoga scriptures, certain sets of exercises were needed to be performed by the patient under the guidance of an expert as per Table 1.

Table 1: The Ashtanga Yoga therapy was divided into three phases

\begin{tabular}{|l|l|}
\hline Ashtanga Yoga therapy/Intervention & Duration \\
\hline Phase 1 & 2 months \\
\hline Phase 2 & 4 months \\
\hline Phase 3 & 6 months \\
\hline
\end{tabular}

Carefully calibrated exercises were performed as per Table 2 under the supervision of an expert Yoga therapist using the principles of Ashtanga Yoga as prescribed in the ancient scriptures.

Table 2: Showing the Ashtanga Yoga Protocol Followed by the Patient

\begin{tabular}{|c|c|c|c|c|}
\hline SN & Exercise & $\begin{array}{l}\text { Initial } 2 \\
\text { months }\end{array}$ & Next 4 months & $\begin{array}{l}\text { Maintenance } \\
\text { Therapy (after } \\
6 \text { months) }\end{array}$ \\
\hline 1. & Om Chanting & 3 times & 3 times & 3 times \\
\hline 2. & $\begin{array}{l}\text { Warm up - } \\
\text { Surya Namaskar A } \\
\text { Surya Namaskar B }\end{array}$ & $\begin{array}{l}1 \text { set, } \\
3 \text { breathe } \\
\text { hold, } 1 \text { set } \\
\text { inflow } \\
\text { Nil }\end{array}$ & $\begin{array}{l}2 \text { set } \\
3 \text { breath hold } \\
2 \text { set in flow } \\
1 \text { set in flow }\end{array}$ & $\begin{array}{l}3 \text { set } \\
3 \text { breath hold } \\
2 \text { set in flow } \\
2 \text { sets in flow }\end{array}$ \\
\hline 3. & $\begin{array}{l}\text { Cervical Pain } \\
\text { a. Pulling the } \\
\text { towel }\end{array}$ & $\begin{array}{l}\text { Up to } 30 \\
\text { sec } \\
3 \text { sets }\end{array}$ & $\begin{array}{l}1 \text { min } \\
3 \text { sets }\end{array}$ & $\begin{array}{l}2 \text { min } \\
3 \text { sets }\end{array}$ \\
\hline 4. & \begin{tabular}{|l|} 
Headache, \\
cervical \\
a. Kapalbharti \\
b. NadhiShodhana \\
c. Brahmari \\
d. Cervical \\
$\quad$ traction \\
e. Pull Ups
\end{tabular} & $\begin{array}{l}30 \text { times, } \\
5 \text { sets } \\
8-10 \text { min } \\
20 \text { times } \\
\text { each } \\
3 \text { min hold } \\
3 \text { sets } \\
3 \text { sets }\end{array}$ & $\begin{array}{l}40 \text { strokes } \\
7 \text { sets } \\
\text { Alternatenostril } \\
\text { breathing } 50 \\
\text { reps } \\
3 \text { min } \\
3 \text { set } \\
3 \text { sets }\end{array}$ & $\begin{array}{l}60 \text { strokes } \\
10 \text { sets } \\
\text { Alternate } \\
\text { nostril } \\
\text { breathing with } \\
\text { retention, } \\
\text { initially started } \\
\text { with } 3: 3 \\
5 \text { min } 3 \text { sets } \\
3 \text { sets }\end{array}$ \\
\hline
\end{tabular}

Functional Training 4-5 days per week.

\section{Posture corrections}

1. Sitting on chair

Keep pillow under hips

Feet on the floor

Roll a towel or blanket and place behind the sacrum region

Height of book or PC should be chest level
2. Sitting on bed

Place pillow under hips

1 or 2 pillows behind sacrum

Height of book for PC should be chest level

3. Lying position

Try sleeping without pillow or use very thin pillow

4. Twisting exercise

Inhale, expand your chest, head at maximum height and then twist

5. Vitamin for healthy hair

Biotin

\section{Discussion}

Ashtanga Yoga continues to be an attractive therapy for Migraine. Several studies pertaining to mindfulness, melatonin, Physical Therapy, exercise, chiropractic manipulation, and acupuncture (16) in migraineurs are ongoing. Several other mind-body intervention studies of meditation, mindfulness, tai chi (13), Yoga (12), Massage therapy, Daith piercing, Hydrotherapy (15), etc have shown positive effects on pain perception and tolerance (14). More research needs to be carried out in order to recommend daith piercings as a physical therapeutic approach due to the risk of infection related to the procedure. Mindfulness and Yoga is the key to reduce rumination and pain catastrophizing, both of which may be the key components of the Fear Avoidance Model of migraine $(10,11)$. Such studies help in deciphering the mechanistic aspect of mind-body interventions (5).

After two weeks from the date of starting similar yoga therapy, the patient started showing improvement on the scale of $2-3$ out of 10 (or $20 \%$ to $30 \%$ in severity of pain). After six weeks, the duration of the pain reduced to 1-2 days/week which was initially 2-3 days/week. After six months the duration of migraine attacks reduced to 2-3 hours once a week only (7-8 improvement out of 10). Her concentration improved, was able to focus better on her social and personal life. Now after 6 months the patient was back to work as normal. She was requested to continue with the maintenance therapy so that there could be no migraine related issues in future $(7,8,9)$.

\section{Conclusion}

The Ashtanga Yoga intervention helped the patient with a severe migraine condition. The therapy improved her condition after 6 weeks of practice. Thus, mind-body interventions may help in providing non-pharmacological and cost-effective chronic pain management among migraineurs.

\section{Acknowledgement}

I thank Dr Saras of the yoga council, haryana for her help in editing and reviewing the manuscript.

\section{Authorship contribution}

Pawandeep Singh has written the article. 


\section{Informed Consent}

Yes.

\section{Source of funding}

Nil.

\section{Conflict of interest}

Nil.

Received Date: 26-05-21; Revised Date: 05-07-21

Accepted Date: 09-07-21

\section{References}

1. P J John, Neha Sharma, Chandra M Sharma, Arvind Kankane. Effectiveness of yoga therapy in the treatment of migraine without aura: a randomized controlled trial. Headache 2007 May.

2. Chou R, Huffman LH. Nonpharmacologic therapies for acute and chronic low back pain: a review of the evidence for an American Pain Society/ American College of Physicians clinical practice guideline. Annals of internal medicine. 2007 Oct 2; 147(7): 492-504

3. Allegri M, Montella S, Salici F, Valente A, Marchesini M, Compagnone C, Baciarello M, Manferdini ME, Fanelli G. Mechanisms of low back pain: a guide for diagnosis and therapy. 2016 Jun 28; 5: F1000 Faculty Rev-1530.

4. Johannes CB, Le TK, Zhou X, Johnston JA, Dworkin RH. The prevalence of chronic pain in United States adults: results of an Internet-based survey.Journal pain. 2010 Nov; 11(11): 1230-9.

5. Rossi P, Di Lorenzo G, Malpezzi MG, et al Prevalence, pattern and predictors of use of complementary and alternative medicine (CAM) in migraine patients attending a headache clinic in Italy. Phalalgia $2005 \mathrm{Jul}$; 25(7): 493-506. 10.1111/j.1468-2982.2005.00898.
6. Andersson GB. Epidemiological features of chronic low-back pain. The lancet. 1999 Aug 14; 354.

7. Von Peter S, Ting W, Scrivani S, et al Survey on the use of complementary and alternative medicine among patients with headache syndromes. June 1, 2002. Volume: 22 issue: 5, page(s): 395-400.

8. Sharma SK, Singh A, Telles S, Balkrishna A. Yoga as an add-on therapy in the management of migraine. Indian J Community Med 2020; 45: 244 .

9. Lemstra M, Stewart B, Olszynski WP. Effectiveness of multidisciplinary intervention in the treatment of migraine: A randomized clinical trial. Headache. 2002 Oct; 42(9): 845-54.

10. Keller A, Meyer B, Wöhlbier HG, Overath $\mathrm{CH}$, Kropp P. Migraine and meditation: characteristics of cortical activity and stress coping in migraine patients, meditators and healthy controls-an exploratory cross-sectional study. Applied psychophysiology and biofeedback. 2016 Sep; 41(3): 307-13.

11. Komandur B, Martin PR, Bandarian-Balooch S. Mindfulness and Chronic Headache/Migraine. The Clinical journal of pain. 2018 Jul 1; 34(7): 638-49.

12. Boroujeni MZ, Marandi SM, Esfarjani F, Sattar M, Shaygannejad V, Javanmard SH. Yoga intervention on blood NO in female migraineurs. Advanced biomedical research. 2015; 4.

13. Xie Y, Hui SS, Ho SC, Suen KP. The effectiveness of 12 -week Tai Chi training in the prophylaxis of episodic migraine: a pilot randomized controlled trial in Chinese women. In Cephalalgia 2017 (p. 334).

14. Wells RE, Beuthin J, Granetzke L. Complementary and integrative medicine for episodic migraine: an update of evidence from the last 3 years. Current pain and headache reports. 2019 Feb; 23(2): 1-0.

15. Sujan MU, Rao MR, Kisan R, Abhishekh HA, Nalini A, Raju TR, Sathyaprabha TN. Influence of hydrotherapy on clinical and cardiac autonomic function in migraine patients. Journal of neurosciences in rural practice. 2016 Jan; 7(01): 109-13.

16. Urits I, Patel M, Putz ME, Monteferrante NR, Nguyen D, An D, Cornett EM, Hasoon J, Kaye AD, Viswanath 0 . Acupuncture and its role in the treatment of migraine headaches. Neurology and therapy. 2020 0ct 1: 1-20. 